\title{
THE
}

\section{Nighttime notifications and compulsivity illuminate the link between emerging adults' cellphone use and sleep-related problems}

Karla Klein Murdock

Sue K. Adams

University of Rhode Island, suekadams@uri.edu

Caroline Crichlow-Ball

Mikael Horissian

Meredith Roberts

Follow this and additional works at: https://digitalcommons.uri.edu/hdf_facpubs

The University of Rhode Island Faculty have made this article openly available.

Please let us know how Open Access to this research benefits you.

This is a pre-publication author manuscript of the final, published article.

Terms of Use

This article is made available under the terms and conditions applicable towards Open Access

Policy Articles, as set forth in our Terms of Use.

\section{Citation/Publisher Attribution}

Murdock, K. K., Adams, S. K., Crichlow-Ball, C., Horissian, M., \& Roberts, M. (2019). Nighttime notifications and compulsivity illuminate the link between emerging adults' cellphone use and sleep-related problems. Psychology of Popular Media Culture, 8(1), 12-21. doi: 10.1037/ppm0000156

Available at: http://dx.doi.org/10.1037/ppm0000156

This Article is brought to you for free and open access by the Human Development and Family Science at DigitalCommons@URI. It has been accepted for inclusion in Human Development and Family Science Faculty Publications by an authorized administrator of DigitalCommons@URI. For more information, please contact digitalcommons-group@uri.edu. 
Nighttime Notifications and Compulsivity Illuminate the Link between Emerging Adults' Cellphone Use and Sleep-Related Problems

Murdock, K.K.

Adams, S.K.

Crichlow-Ball, C.

Horissian, M.

Roberts, $\mathrm{M}$.

\section{IN PRESS}

Psychology of Popular Media Culture 


\begin{abstract}
Although higher levels of cellphone use have been correlated with sleep problems, few studies have investigated specific qualities of cellphone use that may account for this relationship. Recently, significant associations among nighttime cellphone use, compulsive orientation toward cellphone use, and multiple characteristics of compromised sleep were found in a sample of undergraduate students enrolled at a small liberal arts college (Murdock, Horissian, \& CrichlowBall, 2016). The current study expands upon these findings. Data were collected from two samples of undergraduates: 273 students enrolled at a mid-sized state university and 152 selfidentified students recruited through Mechanical Turk. Hierarchical regression analyses were conducted to test the hypotheses that nighttime cellphone notifications and qualities of compulsive cellphone use would predict sleep problems and daytime sleepiness, even after taking into account the overall frequency of cellphone use. Full support for hypotheses was found for both domains of sleep-related functioning in both samples. Findings suggest that qualitative aspects of cellphone use, such as its timing and compulsivity, may be more important to emerging adults' sleep than quantitative aspects of cellphone use, such as the number of texts or time spent on calls. Sleep promotion programs for emerging adults should target specific cellphone use qualities - that is, the when, where, and how of cellphone use - to promote behavior change and improved sleep.
\end{abstract}

Keywords: Emerging adulthood; Cellphone; Sleep; Compulsive 
Cellphones or smartphones are owned by $98 \%$ of emerging adults (i.e., 18-29 year-olds) in the United States (Anderson, 2015). Texting is the most frequently utilized cellphone function in this age group (Smith, 2015). Emerging adults report that on an average day, they send and receive more than 100 texts (Experion Marketing Services, 2013; Murdock, Horissian, \& Crichlow-Ball, 2016) and spend 95 minutes texting (Roberts, Petnji Yaya, \& Manolis, 2014). Most in this age group never (35\%) or rarely (48\%) turn their phones off (Rainie \& Zickuhr, 2015), and a vast majority endorses sleeping with the phone within arm's reach (Lenhart, 2010). In a nationwide poll, more than one third of 18-24 year-olds reported sending and/or receiving texts at 3 a.m. (Experion Marketing Services, 2013).

College students appear to habitually experience daytime sleepiness (Oginska \& Pokorski, 2006), poor sleep quality (Lund, Reider, Whiting, \& Prichard, 2010), and feeling that they did not get enough sleep to function well (Gradisar et al., 2013). The recommended sleep duration for emerging adults is 7-9 hours (Hirshkowitz et al., 2015), but at least 8.5 hours are recommended for optimal functioning and well-being (Lund et al., 2010). Poor sleep quality has been linked with higher levels of negative mood, physical symptoms, stress, use of medications, and persistent psychologicaldistress (Glozier et al., 2010; Lund et al., 2010), and a doseresponse relationship has been demonstrated between sleep duration and multiple domains of psychological functioning (Kalak, Lemola, Brand, Holsboer-Trachsler, \& Grob, 2014). Electronic média use has been identified as a factor contributing to chronic sleep loss in young adults (Owens et al., 2014), but the mechanisms of this association have not been fully investigated.

\section{Cellphone Use and Sleep-Related Functioning}


Perhaps not surprisingly, studies of emerging adults have documented significant associations of quantitative measures of their text messages and/or cellphone calls with aspects of sleep-related functioning such as sleep problems (Murdock, 2013), sleep disturbances (Thomee, Harenstam, \& Hagberg, 2011), and subjective sleep quality (Murdock et al., 2016). Thomée and colleagues (2007) found longitudinal support for texts and calls as a predictor of difficulties falling asleep one year later among young adult men (but not women).

Some studies have specifically investigated links between emerging adults' cellphone habits at night and sleep. Findings have been mixed across different dimensions of sleep-related functioning. Data from the National Sleep Foundation's 2011 Sleep in America poll revealed a significant association of bedtime cellphone use with difficulty falling asleep, but not with later bedtimes (Gradisar et al., 2013). Fossum, Nordnes, Storemark, Bjorvatn, and Pallesen (2014) reported a significant association of bedtime cellphone use with severity of insomnia symptoms, but not with daytime sleepiness. Adams and Kjsler (2013) found that a subset of undergraduates in their university sample endorsed responding to texts and cellphone calls after bedtime, and these students experienced an average of 46 minutes of sleep disruption per week. However, even in this sample as a whole, students reported an average of 25 minutes per week of sleep disruptions due to text messages and cellphone calls after bedtime. In spite of these notable levels of sleep disruption, in this sample neither the total number of daily texts and phone calls nor the totaltime awake due to texts and cellphone calls was significantly correlated with selfreported sleep problems. Li, Lepp, and Barkley (2015) recently found support for a path model linking college students' overall cellphone use and satisfaction with life. One statistically significant path ran from higher levels of overall cellphone use to higher levels of nighttime cellphone use, through greater sleep problems, to lower levels of satisfaction with life. Another 
statistically significant path ran from higher level of overall cellphone use to higher levels of cellphone use during class and study time, to lower grade point average, to lower satisfaction with life.

Taken together, these results reinforce the importance of understanding sleep quality as a foundational aspect of well-being, but leave open the question of exactly how cellphone use may be linked with emerging adults' sleep. Instead of focusing on purely quantitative measures of cellphone use frequency, theoretical models must address multiple layers of habitual cellphonerelated behaviors and cognitions that may help to illuminate links with sleep-related functioning.

\section{Compulsive Qualities of Cellphone Use}

Within recent years, multiple constructs have been deyeloped concerning problematic psychological tendencies toward cellphone use (Billieux, 2012). Some measures have drawn from the behavioral addiction literature to conceptualize cognitive (e.g., thinking about the phone, wanting to check it, and feeling out of sorts when separated from it) and behavioral (e.g., checking the phone and keeping it within arm's reach) aspects of problematic cellphone use (David, Kim, Brickman, Ran, \& Curtis, 2015; Roberts et al., 2014; Walsh, White, \& Young, 2010). Several studies have examined personality and mental health correlates of compulsive/addictive cellphone use (Bianchi \& Phillips, 2005; Billieux, Van Der Linden, \& Rochat, 2008; Harwood, Dooley, Scott, \& Joiner, 2014; Roberts, Pullig, \& Manolis, 2015). For instance, O'Connor and colleagues (2013) utilized factor analysis to identify four factors of the Cell Phone Overuse Scale (CPOS; Jenaro, Flores, Gómez-Vela, González-Gil, \& Caballo, 2007): anticipation; activity interfering; emotional reaction; and problem recognition. They found that subscales were consistently but differentially correlated with outcomes such as impulsivity, problematic alcohol use, and relational attachment style. Perhaps most notably, only the 
anticipation subscale (i.e., thinking about the phone when it is turned off and thinking about new messages that may be received) was significantly associated with a history of motor vehicle crashes.

It appears that only three studies have examined associations between compulsive qualities of cellphone use and emerging adults' sleep characteristics. Jenaro and colleagues (2007) utilized the Cellphone Overuse Scale, which is based on diagnostic criteria parallel to those for pathological gambling, in a study of Spanish undergraduates. Higher scores on this measure were associated with insomnia symptoms, but not with sleep duration. Ferraro, Holfeld, Frankl, Frye, and Halvorson (2015) examined a construct of texting dependency encompassing excessive use as well as texting-related negative emotional reactions, disruption of relationships, and psychological/behavioral symptoms. Using standard thresholds for scores on the Pittsburgh Sleep Quality Index, they found that college students classified as "poor" sleepers had higher levels of texting dependency when compared to "good" sleepers.

Recently, in a sample of undergraduates enrolled at a small liberal arts college, Murdock and colleagues (2016) utilized hierarchical multiple regression analysis to investigate unique associations of the average number of daily text messages, awareness of nighttime cellphone notifications, and compulsion to respond to nighttime notifications with multiple aspects of sleep-related functioning. A greater average number of daily text messages was significantly associated only with subjective sleep quality, but greater awareness of nighttime cellphone notifications was significantly associated with global sleep problems, sleep disruptions, and subjective sleep quality. After partialing out the variance accounted for by daily texts and nighttime notifications, compulsion to respond to nighttime notifications contributed additional unique variance in predicting subjective sleep quality. 
It appears that compulsive or addictive features of cellphone use are common among emerging adults; in a recent nationwide poll of college students in the United States, 10-20\% endorsed such psychological experiences (Smetaniuk, 2014). Therefore, compulsive cellphone tendencies may be an important element of risk for emerging adults to experience compromises in sleep-related functioning.

\section{The Current Study}

This study builds on the findings of Murdock and colleagues (2016), described above, in which cellphone use frequency, nighttime use, and compulsivity were associated with college students' sleep-related functioning. The current study expands on these results by assessing a more robust construct of compulsive cellphone use and by investigating these processes in two additional groups of undergraduates. The Compulsive Cellphone Use Questionnaire was developed for this study to assess affective, cognitive, behavioral, and social aspects of excessive and repetitive cellphone use that is at least partially motivated by anxiety reduction.

Two hypotheses were tested in this study. Hypothesis One was that after taking into account the variance accounted for by overall cellphone use (i.e., daily texts and calls), greater awareness of nighttime cellphone notifications would be significantly associated with poorer sleep-related functioning (i.e., global sleep problems and daytime sleepiness). Hypothesis Two was that after accounting for overall cellphone use and awareness of nighttime cellphone notifications, higher levels of compulsive cellphone use would be associated with poorer sleeprelated functioning.

These hypotheses were tested in two separate samples: undergraduate students enrolled at a mid-sized state university; and self-identified undergraduate students who participated in the study via Amazon's Mechanical Turk (MTurk). MTurk is an online crowdsourcing marketplace 
in which workers (i.e., members of the public) select among thousands of Human Intelligence Tasks (HITs) that are submitted by requesters (i.e., task creators: researchers, businesses). Workers can earn small amounts of monetary compensation for successfully completing tasks. However, if their work fails to meet quality checks, requesters can reject their work and refuse to pay. Workers' acceptance/rejection ratings can affect their eligibility to participate in future tasks.

MTurk is an increasingly popular tool for academic researchers to collect behavioral science data (Chan \& Holosko, 2016). MTurk participants tend to be more ethnically, racially and socioeconomically diverse than participants recruited through more traditional methods (Behrend, Sharek, Meade, \& Wiebe, 2011; Buhrmester, Kwang, \& Gosling, 2011). There is evidence that psychometric characteristics of measures administered via MTurk are consistent with those generated from in-person and other internet samples (Buhrmester et al., 2011; Casler, Bickel, \& Hackett, 2013), and that MTurk workers exhibit superior attention to instructions when compared to participants in traditional college samples (Hauser \& Schwarz, 2016; Ramsey, Thompson, McKenzie, \& Rosenbaum, 2016).

\section{Method}

\section{Participants and Procedure}

Demographic characteristics of Samples One and Two are presented in Table 1.

Constructs for the current study were assessed, and target sample sizes were set, as part of a larger study investigating links between cellphone use and college students' psychosocial wellbeing.

Sample One. Sample One included 273 undergraduate students (90\% female) enrolled at a mid-sized, northeastern, public university and recruited through classes in the Human 
Development and Family Studies Department, in which students from a variety of majors were enrolled. Participants completed an online survey at their convenience and were eligible to earn extra credit. A total of 291 students completed the study, but 13 surveys were excluded from the final dataset because respondents' ages fell more than 3 standard deviations above the mean age of the sample, and five surveys were excluded due to missing data.

Sample Two. Sample Two included 152 individuals (50\% female) who accessed an online survey through Amazon's Mechanical Turk (MTurk). Participants were eligible if they endorsed being at least 18 years of age, living in the United States, and currently enrolled in a 2or 4-year college. Participants were required to have an MTurk acceptance rating of at least 95\%. They were eligible to earn $\$ 0.75$, a typical rate for a 20-minute MTurk survey. Eighteen percent of the sample was enrolled in a 2-year college; $9 \%$ was enrolled in a 4-year community college; and $73 \%$ was enrolled in a 4-year college or university. A total of 161 individuals completed the study, but eight surveys were rejected for containing incorrect responses to two out of the three validity check items (e.g., Choose yourfavorite color from the following: red, car, truck, grass.), and one survey was excluded from the final dataset due to missing data.

\section{Measures}

Questionnaires were presented in the same order across all participants: 1) estimated daily texts and calls; 2) nighttime cellphone use; 3) global sleep problems; 4) daytime sleepiness; 5) compulsive cellphone use; and 6) demographic information.

Participants reported their sex, age, class year, ethnicity, race, and the educational attainment of up to two parents, ranging from 1 (Did not finish high school) to 8 (Doctoral degree). The mean parental education of two parents was calculated. 
Estimated Daily Texts and Calls. Participants were asked to estimate, on an average day, the number of text messages sent and received and the number of minutes spent talking on their cellphone.

Nighttime Cellphone Notifications. Four items were utilized to assess the frequency of cellphone notifications received at night: 1) During an average week, on how many nights do you hear or see cellphone notifications while you are trying to get to sleep? 2) During an average week, on how many nights do you respond to cellphone notifications while you aré trying to get to sleep? 3) During an average week, on how many nights are you awakened by cell phone notifications in the middle of the night, once you have already fallen asleep? 4) During an average night that you are awakened by cell phone notifications after you have fallen asleep, approximately how many times are you awakened? Responses on the first three items could range from zero to seven nights. Responses on item 4 were made on a 6-point scale ranging from "zero nights; never awakened" to "five or more times." Internal consistency of these four items was acceptable in a previous sample drawn from a small liberal arts college $(\alpha=.74$; Murdock et al., 2016) and good in the current Sample One $(\alpha=.83)$ and Sample Two $(\alpha=.86)$. In order to standardize response scales, items were z-scored and summed to create a nighttime cellphone notifications variable.

For descriptive purposes, participants were asked to report the typical location of their cellphone at night. Results are presented in Figure 1.

Compulsive Cellphone Use. The 12-item Compulsive Cellphone Use Questionnaire (CCQ) was developed for this study to assess compulsive qualities of cellphone use, including affective, cognitive, and behavioral aspects of excessive and repetitive cellphone use that is at least partially motivated by anxiety reduction, as well as activity and relationship interference 
that results from this tendency. The CCQ is presented in Table 2. Participants respond to items on 5-point scales ranging from 1 ("not at all") to 5 ("very") or from 1 ("never") to 5 ("almost always").

Exploratory factor analyses were conducted to examine the structure of the CCQ in Samples One and Two. Using Cattell's (1966) scree test one factor was retained, which accounted for $50.9 \%$ and $50.1 \%$ of the variance in Samples One and Two, respectively. Factor loadings of the 12 items ranged from .58 to .81 and from .44 to .81 in Samples One and Two. Cronbach's alpha was excellent in Sample One $(\alpha=.91)$ and Sample Two $(\alpha=.90)$, and item analysis revealed no item deletions that would improve the internal consistency of the measure. Responses were summed to form a total score, with higher scores indicating higher levels of compulsive cellphone use.

Global Sleep Problems. Sleep problems were assessed with the 22-item Pittsburgh Sleep Quality Index (PSQI; Buysse, Reynolds, Monk, Berman, \& Kupfer, 1989). The PSQI is a widely used instrument constructed of seyen component scores: subjective sleep quality, latency, duration, habitual sleep efficiency, sleep disturbances, use of sleeping medication, and daytime dysfunction. Raw scores on these components are recoded to a range of 0 to 3 . The seven component scores are summed to create a global sleep problems total score with higher scores indicating more troubled sleep.

Daytime Sleepiness. A modified version of the Epworth Sleepiness Scale for Children (ESS; Johns, 1991) was utilized to assess daytime sleepiness. Some items were altered to fit a college lifestyle. Participants responded to 12 situations (e.g., "sitting in class" or "as a passenger in a car for more than 15 minutes") by rating their likelihood to feel sleepy on a 4-point scale ranging from 0 ("would never feel sleepy or doze off" to 3 ("high chance of feeling sleepy or 
dozing off"). This modified measure is available upon request to the corresponding author. Internal consistency of this measure was good in a previous sample drawn from a small liberal arts college ( $\alpha=.85$; Murdock et al., 2016) and excellent in the current Sample One $(\alpha=.90)$ and Sample Two $(\alpha=.90)$. Items were summed to create a total score with higher scores indicating greater sleepiness.

\section{Results}

\section{Preliminary Analyses}

As depicted in Figure 1, 96\% of Sample One and $85 \%$ of Sample Two reported keeping their cellphone within arm's reach at night.

Psychometric properties of primary study variables (i.e., estimated daily texts; estimated daily call minutes; nighttime cellphone notifications; compulsive cellphone use; global sleep problems; and daytime sleepiness) for Samples One and Two are presented in Table 3. Table 4 presents bivariate correlations among primarystudy variables and subscales of the Pittsburgh Sleep Quality Index.

Among primary study variables, in Sample Two only, estimated number of daily cellphone call minutes was positively correlated with estimated number of daily texts $(r=.24, p$ $=.004)$ and with nighttime cellphone notifications $(r=.30, p<.001)$. The pattern of associations of all other cellphone use variables (daily texts, nighttime cellphone use, and compulsive cellphone use) with primary sleep-related variables (global sleep problems and daytime sleepiness) was similar across the two samples, and statistically significant correlational results are presented below for Samples One and Two, respectively. Estimated number of daily texts was significantly correlated with nighttime cellphone notifications $(r=.20, p=.001 ; r=.39, p<$ $.001)$ and compulsive cellphone use $(r=.17, p=.006 ; r=.19, p=.020)$. Nighttime cellphone 
notifications was significantly associated with compulsive cellphone use $(r=.31, p<.001 ; r=$ $.41, p<.001)$, global sleep problems $(r=.22, p<.001 ; r=.35, p<.001)$, and daytime sleepiness $(r=.26, p<.001 ; r=.19, p=.017)$. Compulsive cellphone use was significantly correlated with global sleep problems $(r=.18, p=.003 ; r=.34, p<.001)$ and daytime sleepiness $(r=.33, p<$ $.001 ; r=.51, p<.001)$. Global sleep problems was significantly correlated with daytime sleepiness in both samples $(r=.43, p<.001 ; r=.44, p<.001)$

Sex and age effects for primary study variables were examined in preliminary analyses of both samples. Age was not correlated with any primary study variable in either sample. In Sample One, independent samples $t$-tests revealed significantly higher levels of estimated daily cellphone call minutes for women $(n=244, M=31.03, S D=33.92)$ compared to men $(n=27, M$ $=16.93, S D=25.04), t(37)=2.67, p=.011$. Similarly in Sample Two, significantly higher levels of daily calls were also reported by women $(n=76, M=39.64, S D=47.29)$ compared to men $(n$ $=75, M=24.53, S D=30.28), t(128)=2.34, p=.021$. In Sample One, women reported significantly higher levels of compulsive cellphone use $(n=246, M=33.63, S D=9.56)$ when compared to men $(n=27, M=29.00, S D=8.58), t(271)=2.41, p=.016$. However, in Sample Two, levels of compulsive céllphone use were not significantly different between women $(n=$ $76, M=32.40, S D=10.06)$ and $\operatorname{men}(n=75, M=30.47, S D=9.88), t(149)=1.19, p=.237$. In Sample Two, levels of global sleep problems were significantly higher among women $(n=76, M$ $=6.55, S D=3.01)$ compared to men $(n=75, M=5.37, S D=2.68), t(149)=2.54, p=.012$.

However, in Sample One, there were no significant differences in global sleep problems between women $(n=246, M=6.24, S D=3.02)$ and $\operatorname{men}(n=27, M=6.48, S D=3.94), t(29)=.31, p=$ .755 .

\section{Hypothesis Testing}


Hierarchical multiple regression analyses were conducted to test hypotheses. Initially, age, sex, race, ethnicity, and parent education were entered in Block One. This block of demographic variables did not account for significant variance in global sleep problems or daytime sleepiness in Sample One or Sample Two. However, sex emerged as a significant individual predictor of global sleep problems in Sample Two. Hierarchical regression models were tested with variables entered in the following blocks: 1) participant sex; 2) estimated number of daily texts and estimated number of daily cellphone call minutes; 2) nighttime cellphone notifications; and 3) compulsive cellphone use. Two regression analyses were conducted in each sample to examine the criterion variables of global sleep problems and daytime sleepiness. Cook's distance values were calculated in each regression model and no values over 1 were identified in Sample One or Sample Two.

Global Sleep Problems. Results are presented in Table 5. In Sample One, blocks one and two did not account for significant variance in the outcome. In the third block, nighttime cellphone notifications was a significant predictor $(\beta=.21, t=3.35, p=.001)$, accounting for $4 \%$ of unique variance. In the fourth block, compulsive cellphone use was a significant predictor $(\beta=$ $.13, t=2.08, p=.038)$ and accounted for $2 \%$ of unique variance. This model predicted $6 \%$ of the variance in global sleep problems.

In Sample Two, sex (males coded as 1, females coded as 2) was a significant predictor of global sleep problems ( $\beta=.20, t=2.54, p=.012)$, accounting for $4 \%$ of unique variance. An additional $4 \%$ of variance was accounted for in the second block, with estimated daily texts emerging as a significant predictor $(\beta=.20, t=2.47, p=.015)$. In the third block, nighttime cellphone notifications was a significant predictor $(\beta=.41, t=4.89, p<.001)$, accounting for $13 \%$ of unique variance. In the final block, compulsive cellphone use was a significant predictor 
$(\beta=.19, t=2.42, p=.017)$ and accounted for $3 \%$ of unique variance. This model predicted $24 \%$ of the variance in global sleep problems.

Daytime Sleepiness. Results are presented in Table 6. In Sample One, blocks one and two did not account for significant variance in the outcome. Nighttime cellphone notifications was a significant predictor in the third block $(\beta=.21, t=3.43, p=.001)$, accounting for $4 \%$ of unique variance. In the fourth block, compulsive cellphone use was a significant predictor $(\beta=$ $.28, t=4.40, p<.001)$ and accounted for $7 \%$ of unique variance. This model predicted $12 \%$ of the variance in daytime sleepiness.

In Sample Two, blocks one and two did not account for significant variance in the outcome. In the third block, nighttime cellphone notifications was a significant predictor ( $\beta=$ $.21, t=2.25, p=.026$ ), accounting for $3 \%$ of unique variance. In the third block, compulsive cellphone use was a significant predictor $(\beta=.51, t=6.39, p<.001)$ and accounted for $21 \%$ of unique variance. This model predicted $26 \%$ of the variance in daytime sleepiness.

\section{Additional Analyses}

Given the statistically significant sex differences in compulsive cellphone use (Sample One) and global sleep problems (Sample Two), hierarchical regression analyses were recalculated with the interaction of sex $\times$ compulsive cellphone use entered in the fifth block. In Sample One, the interaction accounted for $2 \%$ of unique variance in global sleep problems ( $\beta=$ $.95, t=2.23, p=.027)$, but accounted for no additional variance in daytime sleepiness $(\beta=.04, t$ $=0.09, p=.927)$. In Sample Two, the interaction was not significant for global sleep problems $(\beta$ $=.05, t=0.20, p=.840)$ or daytime sleepiness $(\beta=-.28, t=1.20, p=.231)$.

To decompose the significant interaction, regression analyses of global sleep problems in Sample One were conducted in subsamples of females and males, with variables entered as 
follows: 1) estimated number of daily texts and estimated number of daily cellphone call minutes; 2) nighttime cellphone notifications; and 3) compulsive cellphone use. For females ( $n=$ 238), nighttime notifications was a significant predictor in the second block $(\beta=.21, t=3.27, p$ $=.001$ ), accounting for $4 \%$ of unique variance, and compulsive cellphone use was a significant predictor in the third block $(\beta=.19, t=2.78, p=.006)$, accounting for an additional $3 \%$ of variance. This model accounted for $8 \%$ of the variance in global sleep problems for females. The model accounted for $10 \%$ of the variance for males $(n=26)$, but there were no statistically significant individual predictor variables.

\section{Discussion}

The results of this study build upon evidence from previous research (Murdock et al., 2016) that the timing and compulsivity of cellphone use can explain unique variance in the sleeprelated functioning of college students. In comparison to the cursory, one-item measure of compulsion to check nighttime notifications utilized in the previous study, the current study utilized a more comprehensive measure of compulsive cellphone use. Whereas the previous study examined undergraduates at a small southeastern private liberal arts university, the current study investigated a sample of students at a mid-sized northeastern public university and students in a nationwide MTurk sample. The study by Murdock et al. (2016) and the current study examined two common dimensions of sleep-related functioning: global sleep problems and daytime sleepiness.

In the current study, both nighttime notifications and compulsive cellphone use were significantly associated with global sleep problems and daytime sleepiness across both samples. Both Hypotheses One and Two were fully supported. Effect sizes for the full hierarchical regression models ranged from small to medium/large (i.e., $R^{2}$ of $6 \%-26 \%$ ). Very little of this 
variance was accounted for by overall cellphone use (i.e., estimated daily texts and calls); daily texts emerged as a significant predictor only in the model predicting global sleep problems in Sample Two. In correlational analyses of Pittsburgh Sleep Quality Index subscales, the number of daily texts was significantly positively correlated with sleep disturbance and negatively correlated with daytime dysfunction, only for Sample One. These findings echo those from the previous study, in which daily texts was significantly negatively correlated with subjective sleep quality but was not significantly associated with most self-reported and actigraphy-measured sleep indicators including sleep problems, daytime sleepiness, sleep disruptions, onset latency, wake after sleep onset, and sleep duration (Murdock et al., 2016). Thus, a direct and consistent association between overall rates of texting and sleep-related functioning is not indicated within these college samples. On the contrary, nighttime cellphone notifications and compulsive cellphone use were significantly correlated with multiple sleep indicators across both samples in the current study.

A majority of college students in this study endorsed keeping their cellphone within arm's reach during sleeping hours. Although most college students are physically close to their cellphones at night, their awareness of nighttime notifications may differ. Greater awareness may reflect a propensity toward compulsive cellphone use; in both current samples these constructs were significantly positively correlated. Even so, in the current study compulsive tendencies accounted for significant unique variance in global sleep problems and daytime sleepiness over and above the variance accounted for by awareness of nighttime notifications. Similarly, in a previous sample of college students, compulsion to check nighttime notifications accounted for significant variance in sleep diary-measured subjective sleep quality over and above the variance accounted for by awareness of nighttime notifications (Murdock et al., 2016). It is possible that 
some underlying construct, such as anxiety, drives both awareness of nighttime notifications and compulsive cellphone use. For instance, emerging adults who experience anxiety may be more likely to keep their phones in close proximity during the day and/or night as a safety object and/or in order to avoid missing out on information or interactions. Over time, this habit of close proximity may lead to nighttime distractions and/or potentiate the development of compulsive tendencies.

\section{Study Limitations}

Several methodological characteristics of the current study should be considered in interpreting its findings. First, the current study did not include objective measures of cellphone usage or sleep-related functioning. Questionnaire measures were utilized to measure all constructs, which increases the likelihood of self-report bias. Second, the cross-sectional nature of the current data precludes drawing firm conclusions about the direction of effects between cellphone use characteristics and sleep-related functioning. That is, the experience of sleep disturbances could make it more likely that someone would engage in nighttime cellphone use and/or would develop a pattern of compulsivity in cellphone use. Indeed, in a recent longitudinal study of Canadian college students, Tavernier and Willoughby (2014) concluded that sleep problems may predispose individuals to engage in higher levels of bedtime technology use in the forms of TV watching and use of social media sites. Additional longitudinal research is necessary to clarify how patterns of cellphone use and sleep characteristics emerge within and across adolescence and emerging adulthood.

Finally, although participants from a variety of sociocultural backgrounds participated in this study, Samples One and Two did not represent the full demographic diversity of college students in the United States. 


\section{Future Directions}

Although the current study expanded upon Murdock and colleagues' (2016) work by investigating a multifaceted, instead of a narrowly focused, construct of compulsive cellphone use, future research should investigate this construct in even greater depth. For instance, recent studies have identified specific cellphone-related psychological processes associated with problematic health and behavioral outcomes (O’Connor et al., 2013). Furthermore, different mental health implications have been revealed for cellphone use that is motivated by escaping from boredom versus avoiding emotionally activating situations (Panova \& Lleras, 2016). It is likely that associations between compulsive cellphone use and sleep-related functioning differ across developmental periods, so future research should examine both younger and older samples. A more nuanced investigation of cognitions, behaviors, and emotions involved in compulsive cellphone use may be fruitful for the ereation of empirically based sleep-related interventions.

Sex-specific patterns in cellphone use and sleep were explored on only a superficial basis in the current study. Females were found to have significantly higher levels of compulsive cellphone use than males in Sample One, and follow-up analyses revealed that nighttime notifications and compulsive cellphone use were significantly positively associated with global sleep problems for females but not for males. Unfortunately, the interpretation of these results is complicated by the extreme overrepresentation of females in Sample One, and the lack of statistical power to detect significant effects in the male subsample. Although no significant sex differences in compulsive cellphone use were found in Sample Two, or in compulsion to respond to nighttime notifications in a previous college sample (Murdock et al., 2016), some previous studies have found higher levels of attachment to or dependence upon cellphones among female 
emerging adults when compared to males (Augner \& Hacker, 2012; Geser, 2006; Roberts et al., 2014).

Several factors should be investigated to illuminate possible sex differences in the association of cellphone use and sleep-related functioning. First, there is evidence that males and females experience different motivations for cellphone use (Grellhesl \& Punyanunt-Carter, 2012) and cellphone activity choices (Kimbrough, Guadagno, Muscanell, \& Dill, 2013; Roberts et al., 2014). These motivations and activities may vary in their propensity to compromise sleep, and might account for inconsistently observed sex-related differences in cellphone-sleep relationships. Also, college-aged females are predisposed to higher levels of anxiety and depression than males, and these disorders significantly impact sleep (Adams \& Kisler, 2013). Future studies should assess individual difference variables such as personality characteristics or symptoms of psychopathology, along with measures of cellphone compulsivity. These factors may provide important context for understanding sex-specific trajectories of cellphone use and sleep.

\section{Conclusions}

The current study tested a theoretical model linking qualitative aspects of cellphone use with sleep-related functioning in two samples of undergraduate students. The results of this study, along with findings from a recent study (Murdock et al., 2016), provided evidence from three samples that nighttime cellphone use and compulsive cellphone use are associated with dimensions of sleep-related functioning, whereas overall cellphone use is not consistently associated with sleep. Thus, it may be more productive for emerging adults' sleep promotion interventions to focus on timing and compulsivity of cellphone use instead of targeting overall 
reductions in cellphone use. Identifying the underlying cognitive, behavioral, and affective processes that influence compulsive cellphone use may be fruitful in creating behavior change. 


\section{Reference}

Adams, S. K., \& Kisler, T. S. (2013). Sleep quality as a mediator between technology-related sleep quality, depression, and anxiety. Cyberpsychology, Behavior, and Social Networking, 16(1), 25-30. http://doi.org/10.1089/cyber.2012.0157

Anderson, M. (2015, October 29). Technology Device Ownership: 2015. Retrieved from http://www.pewinternet.org/2015/10/29/technology-device-ownership-2015/

Augner, C., \& Hacker, G. (2012). Associations between problematic mobile phone use and psychological parameters in young adults. International Journal of Public Health, 57, 437-441. http://doi.org./10.1007/s00038-011-0234-z

Behrend, T. S., Sharek, D. J., Meade, A. W., \& Wiebe, E. N. (2011). The viability of crowdsourcing for survey research. Behavior Research Methods, 43(3), 800-813. http://doi.org/10.3758/s13428-011-0081-0

Bianchi, A., \& Phillips, J. G. (2005). Psychological Predictors of Problem Mobile Phone Use. CyberPsychology \& Behavior, 8(1), 39-51.

Billieux, J. (2012). Problematic use of the mobile phone: A literature review and a pathways model. Current Psychiatry Reviews, 8(4), 299-307. http://doi.org/10.2174/157340012803520522

Billieux, J., Van Der Linden, M., \& Rochat, L. (2008). The role of impulsivity in actual and problematic use of the mobile phone. Applied Cognitive Psychology, 22(9), 1195-1210. http://doi.org/10.1002/acp.1429

Buhrmester, M., Kwang, T., \& Gosling, S. D. (2011). Amazon’s Mechanical Turk: A new source of inexpensive, yet high-quality, data? Perspectives on Psychological Science, 6(1), 3-5. http://doi.org/10.1177/1745691610393980 
Buysse, D. J., Reynolds, C. F., Monk, T. H., Berman, S. R., \& al, et. (1989). The Pittsburgh Sleep Quality Index: A new instrument for psychiatric practice and research. Psychiatry Research, 28(2), 193-213.

Casler, K., Bickel, L., \& Hackett, E. (2013). Separate but equal? A comparison of participants and data gathered via Amazon's MTurk, social media, and face-to-face behavioral testing. Computers in Human Behavior, 29(6), 2156-2160. http://doi.org/10.1016/j.chb.2013.05.009

Cattell, R. B. (1966). The scree test for the number of factors. Multivariate Behavioral Research, 1, 245-276. http://dx.doi.org/10.1207/s15327906mbr0102_10

Chan, C., \& Holosko, M. J. (2016). An overview of the use of Mechanical Turk in behavioral sciences: Implications for social work. Research on Social Work Practice, 26(4), 441448. http://doi.org/10.1177/1049731515594024

David, P., Kim, J.-H., Brickman, J. S., Ran, W., \& Curtis, C. M. (2015). Mobile phone distraction while studying. NewMedia \& Society, 17(10), 1661-1679. http://doi.org/10.1177/1461444814531692

Experion Marketing Services. (2013). The 2013 Digital Marker. Retrieved from http://www.experian.com/assets/marketing-services/reports/2013-digital-marketerdownload.pdf?SP_MID=768\&SP_RID $=1097370$

Ferraro, F., Holfeld, B., Frankl, S., Frye, N., \& Halvorson, N. (2015). Texting/iPod dependence, executive function and sleep quality in college students. Computers in Human Behavior, 49, 44-49. http://doi.org/10.1016/j.chb.2015.02.043

Fossum, I. N., Nordnes, L. T., Storemark, S. S., Bjorvatn, B., \& Pallesen, S. (2014). The association between use of electronic media in bed before going to sleep and insomnia 
symptoms, daytime sleepiness, morningness, and chronotype. Behavioral Sleep Medicine, 12(5), 343-357. http://doi.org/10.1080/15402002.2013.819468

Geser H. Are girls (even) more addicted? Some gender patterns of cell phone usage. Sociology in Switzerland: Sociology of the Mobile Phone. 2006 Retrieved February 2017 from http://socio.ch/mobile/t_geser3.pdf.

Glozier, N., Martiniuk, A., Patton, G., Ivers, R., Li, Q., Hickie, I., Senserrick, T., Woodward, M., Norton, R., Stevenson, M. (2010). Short sleep duration in prevalent and persistent psychological distress in young adults: the DRIVE study. Sleep, 33, 1139-1145. http://doi.org/2010-18778-004

Gradisar, M., Wolfson, A. R., Harvey, A. G., Hale, L., Rosenberg, R., \& Czeisler, C. A. (2013). The sleep and technology use of Americans: findings from the National Sleep Foundation's 2011 Sleep in America poll. Journal of Clinical Sleep Medicine: JCSM: Official Publication of the American Academy of Sleep Medicine, 9(12), 1291-1299. http://doi.org/10.5664/jcsm.3272

Grellhesl, M., \& Punyanunt-Carter, N. M. (2012). Using the uses and gratifications theory to understand gratifications sought through text messaging practices of male and female undergraduate students. Computers in Human Behavior, 28(6), 2175-2181. http://doi.org/10.1016/j.chb.2012.06.024

Harwood, J., Dooley, J. J., Scott, A. J., \& Joiner, R. (2014). Constantly connected-The effects of smart-devices on mental health. Computers in Human Behavior, 34, 267-272. http://doi.org/10.1016/j.chb.2014.02.006 
Hauser, D. J., \& Schwarz, N. (2016). Attentive turkers: MTurk participants perform better on online attention checks than do subject pool participants. Behavior Research Methods, 48(1), 400-407. http://doi.org/10.3758/s13428-015-0578-z

Hirshkowitz, M., Whiton, K., Albert, S., Alessi, C., Bruni, O., Albert, S., DonCarlos, L., Hazen, N., Herman, J., Adams Hillard, P., Katz, E., Kheriandish-Gozal, L., Neubauer, D., O'Donnell, A., Ohayon, M., Peever, J., Rawding, R., Sachdeva, R., Setters, B., Vitiello, M., \& Ware, J. (2015). National Sleep Foundation's updated sleep duration recommendations: final. Sleep Health, 1, 233-243. http://dx.doi.org/10.1016/j.sleh.2015.10.004

Jenaro, C., Flores, N., Gómez-Vela, M., González-Gil, F., \& Cáballo, C. (2007). Problematic internet and cell-phone use: Psychological behavioral, and health correlates. Addiction Research \& Theory, 15(3), 309-320. http://doi.org/10.1080/16066350701350247

Johns, M. W. (1991). A new method for measuring daytime sleepiness: The Epworth Sleepiness Scale. Sleep: Journal of Sleep Research \& Sleep Medicine, 14(6), 540-545.

Kalak, N., Lemola, S., Brand, S., Holsboer-Trachsler, E., \& Grob, A. (2014). Sleep duration and subjective psychological well-being in adolescence: a longitudinal study in Switzerland and Norway. Neuropsychiatric Disease and Treatment, 10, 1199-1207. http://doi.org/10.2147/NDT.S62533

Kimbrough,A. M., Guadagno, R. E., Muscanell, N. L., \& Dill, J. (2013). Gender differences in mediated communication: Women connect more than do men. Computers in Human Behavior, 29(3), 896-900. http://doi.org/10.1016/j.chb.2012.12.005

Lenhart, A. (2010, September 2). Cell phones and American adults. Pew Research Center. Retrieved from http://www.pewinternet.org/2010/09/02/cell-phones-and-american-adults/ 
Li, J., Lepp, A., \& Barkley, J. E. (2015). Locus of control and cell phone use: Implications for sleep quality, academic performance, and subjective well-being. Computers in Human Behavior, 52, 450-457. http://doi.org/10.1016/j.chb.2015.06.021

Lund, H., Reider, B., Whiting, A., \& Prichard, J. (2010). Sleep patterns and predictors of disturbed sleep in a large population of college students. Journal of Adolescent Health, 46, 124-132. http://doi.org/10.1016/j.jadohealth.2009.06.016

Murdock, K. K. (2013). Texting while stressed: Implications for students' burnout, sleep, and well-being. Psychology of Popular Media Culture, 2(4), 207-221. http://doi.org/10.1037/ppm0000012

Murdock, K. K., Horissian, M., \& Crichlow-Ball, C. (2016). Emerging Adults' Text Message Use and Sleep Characteristics: A Multimethod, Naturalistic Study. Behavioral Sleep Medicine, 1-14. http://doi.org/10.1080/15402002.2015.1120203

O'Connor, S. S., Whitehill, J. M., King, K. M., Kernic, M. A., Boyle, L. N., Bresnahan, B. W., ... Ebel, B. E. (2013). Compulsive cell phone use and history of motor vehicle crash. Journal of Adolescent Health, 53(4), 512-519. http://doi.org/10.1016/j.jadohealth.2013.05.015

Oginska, H., \& Pokorski, J. (2006). Fatigue and mood correlates of sleep length in three agesocial groups: School children, students, and employees. Chronobiology International, 23, 1317-1328. http://doi.org/ 10.1080/07420520601089349

Owens, J., Adolescent Sleep Working Group, \& Committee on Adolescence (2014). Insufficient sleep in adolescents and young adults: An update on causes and consequences. Pediatrics, 134, e921-e932). http//doi.org/10/1542/ped.2014-1696 
Panova, T., \& Lleras, A. (2016). Avoidance or boredom: Negative mental health outcomes associated with use of Information and Communication Technologies depend on users' motivations. Computers in Human Behavior, 58, 249-258. http://doi.org/10.1016/j.chb.2015.12.062

Rainie, L., \& Zickuhr, K. (August 2015). Americans' Views on Mobile Etiquette. Pew Research Center. Retrieved from: http://www.pewinternet.org/2015/08/26/americans-views-onmobile-etiquette/

Ramsey, S. R., Thompson, K. L., McKenzie, M., \& Rosenbaum, A. (2016). Psychological research in the internet age: The quality of web-based data. Computers in Human Behavior, 58, 354-360. http://doi.org/10.1016/j.chb.2015.12.049

Roberts, J. A., Petnji Yaya, L. H., \& Manolis, C. (2014). The invisible addiction: Cell-phone activities and addiction among male and female college students. Journal of Behavioral Addictions, 3(4), 254-265. http://doi.org/10.1556/JBA.3.2014.015

Roberts, J. A., Pullig, C., \& Manolis, C. (2015). I need my smartphone: A hierarchical model of personality and cell-phone addiction. Personality and Individual Differences, 79, 13-19. http://doi.org/10.1016/j.paid.2015.01.049

Smetaniuk, P. (2014). A preliminary investigation into the prevalence and prediction of problematic cell phone use. Journal of Behavioral Addictions, 3(1), 41-53. http://doi.org/10.1556/JBA.3.2014.004

Smith, A. (2015, April 1). U.S. Smartphone Use in 2015. Pew Research Center. Retrieved from http://www.pewinternet.org/2015/04/01/us-smartphone-use-in-2015/ 
Tavernier, R., \& Willoughby, T. (2014). Sleep problems: Predictor or outcome of media use among emerging adults at university? Journal of Sleep Research, 23(4), 389-396. http://doi.org/10.1111/jsr.12132

Thomée, S., Eklöf, M., Gustafsson, E., Nilsson, R., \& Hagberg, M. (2007). Prevalence of perceived stress, symptoms of depression and sleep disturbances in relation to information and communication technology (ICT) use among young adults-An explorative prospective study. Computers in Human Behavior, 23(3), 1300-1321.

Thomee, S., Harenstam, A., \& Hagberg, M. (2011). Mobile phone use and stress, sleep disturbances, and symptoms of depression among young adults - a prospective cohort study. BMC Public Health, 11(1), 66.

Walsh, S. P., White, K. M., \& Young, D. (2010). Needing to connect: The effect of self and others on young people's involvement with their mobile phones. Australian Journal of Psychology, 62(4), 194-203. http://doi.org/10.1080/00049530903567229 


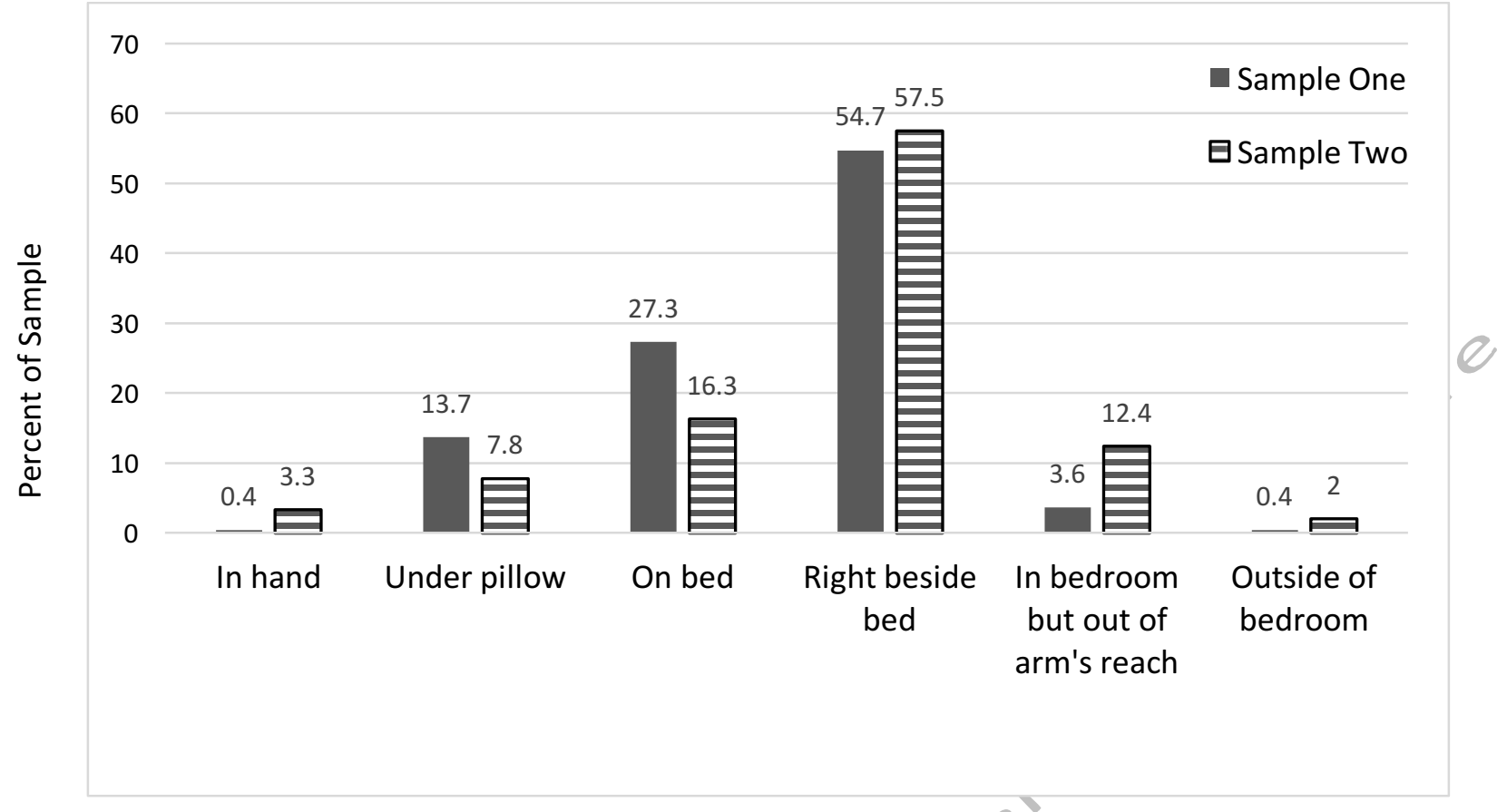

Figure 1. Habitual Location of Cellphone at Night 
Table 1

Demographic Characteristics of Participants

\begin{tabular}{|c|c|c|c|c|c|c|}
\hline & \multicolumn{3}{|c|}{ Sample One $(N=273)$} & \multicolumn{3}{|c|}{ Sample Two $(N=152)$} \\
\hline & $M(S D)$ & Range & $\%(n)$ & $M(S D)$ & Range & $\%(n)$ \\
\hline Sex & & & $90 \%$ (246) female & & & $50 \%$ (76) female \\
\hline Age & $20.7(1.40)$ & $18-28$ & & $21.7(1.77)$ & $18-26$ & \\
\hline Class year & & & $\begin{array}{l}\text { 10\% (26) First year } \\
33 \% \text { (91) Sophomore } \\
33 \% \text { (90) Junior } \\
24 \% \text { (66) Senior }\end{array}$ & 4 & .2 & $\begin{array}{l}12 \%(18) \text { First year } \\
27 \%(41) \text { Sophomore } \\
26 \%(40) \text { Junior } \\
25 \%(38) \text { Senior } \\
10 \%(15) 5^{\text {th }}-6^{\text {th }} \text { year }\end{array}$ \\
\hline Ethnicity & & & $\begin{array}{l}9 \%(25) \\
\text { Hispanic/Latino }\end{array}$ & & & $\begin{array}{l}\text { 15\% (22) } \\
\text { Hispanic/Latino }\end{array}$ \\
\hline$e^{k}$ & $5^{5}$ & & $\begin{array}{l}86 \% \text { (235) White } \\
8 \% \text { (23) Black } \\
4 \% \text { (11) Asian } \\
1 \%(3) \text { American } \\
\text { Indian / Alaska Native } \\
1 \%(4) \text { Hawaiian / } \\
\text { Pacific Islander }\end{array}$ & & & $\begin{array}{l}\text { 76\% (115) White } \\
\text { 13\% (20) Black } \\
\text { 9\% (13) Asian } \\
\text { 1\% (2) American } \\
\text { Indian / Alaska } \\
\text { Native } \\
\text { 1\% (2) Hawaiian / } \\
\text { Pacific Islander }\end{array}$ \\
\hline $\begin{array}{l}\text { Parental } \\
\text { Education }^{2}\end{array}$ & $4.58(1.82)$ & $1-8$ & & $4.35(1.85)$ & $1-8$ & \\
\hline
\end{tabular}


${ }^{1}$ Participants endorsed all racial identities that applied.

${ }^{2}$ Mean for up to two parents. 1 = did not finish high school; 4 = specialized training after high school; 5 = 2-year associates degree; 8 = doctoral degree. 
Table 2

Compulsive Cellphone Use Questionnaire (CCQ)

\begin{tabular}{|c|c|}
\hline & Think about the past month when responding to the following items. \\
\hline $1^{\mathrm{a}}$ & How difficult is it for you to ignore an incoming text message? \\
\hline $2^{\mathrm{a}}$ & $\begin{array}{l}\text { How hesitant are you to turn off notifications or temporarily disable your phone from incoming calls } \\
\text { or messages? }\end{array}$ \\
\hline $3^{a}$ & How hesitant are you to put physical distance between you and your phone? \\
\hline $4^{\mathrm{a}}$ & How much do you feel responsible for being accessible via cell phone at afl times? \\
\hline $5^{a}$ & How anxious do you feel when you are not accessible via cellphone? \\
\hline $6^{\mathrm{b}}$ & $\begin{array}{l}\text { How often do you check repeatedly (e.g., press the phone's "on" button) in anticipation of a text } \\
\text { response from someone? }\end{array}$ \\
\hline $7^{b}$ & $\begin{array}{l}\text { When unlocking your phone with the intention of performing a non-text-related activity, how often } \\
\text { do you get sidetracked by reading or responding to text messages? }\end{array}$ \\
\hline $8^{b}$ & $\begin{array}{l}\text { If a question comes up and you don't know the answer, how often do you feel the need to look it up } \\
\text { immediately on your smartphone? }\end{array}$ \\
\hline $9^{b}$ & How often do others seem to think that you use your cellphone too much? \\
\hline $10^{b}$ & How often does your cellphone use interfere with other activities that you are trying to do? \\
\hline $11^{\mathrm{b}}$ & $\begin{array}{l}\text { How often has your cellphone use prompted disagreements or bad feelings between you and } \\
\text { someone in your family? }\end{array}$ \\
\hline $12^{b}$ & $\begin{array}{l}\text { How often has your cellphone use prompted disagreements or bad feelings between you and one of } \\
\text { your friends? }\end{array}$ \\
\hline
\end{tabular}

${ }^{\mathrm{a}} 1=$ Not at all; 2 = A little bit; 3 = Somewhat; 4 = Quite; 5 = Very

${ }^{\mathrm{b}} 1$ = Never; 2 = Rarely; 3 = Sometimes; 4 = Often; 5 = Almost Always 
Table 3

Psychometric Properties of Primary Study Measures

\begin{tabular}{|c|c|c|c|c|c|c|}
\hline & & aple One $(N=2$ & & $\mathrm{Sa}$ & e Two ( $N$ & \\
\hline & $M(S D)$ & Range & $\alpha$ & $M(S D)$ & Range & $\alpha$ \\
\hline Estimated number of daily texts & $233(274)$ & $2-1500^{1}$ & & $130(154)$ & $0-669^{2}$ & -- \\
\hline $\begin{array}{l}\text { Estimated number of daily cellphone call } \\
\text { minutes }\end{array}$ & $29(33)$ & $0-140^{3}$ & & $38(83)$ & $0-204^{4}$ & -- \\
\hline Nighttime cellphone notifications ${ }^{5}$ & $0(3.33)$ & $-3.78-9.60$ & .83 & $11.26(7.16)$ & $4-30$ & .86 \\
\hline Compulsive cellphone use & $33.15(9.55)$ & $12-60$ & .91 & $31.40(9.97)$ & $12-60$ & .91 \\
\hline Global sleep problems & $6.27(3.12)$ & $1-18$ & -- & $5.95(2.91)$ & $0-14$ & -- \\
\hline Daytime sleepiness & $25.94(7.32)$ & $12-48$ & .90 & $25.11(7.37)$ & $12-48$ & .90 \\
\hline
\end{tabular}

${ }^{1} 5$ outliers were replaced with values at 3 SD above the mean.

${ }^{2} 6$ outliers were replaced with values at 3 SD above the mean.

37 outliers were replaced with values at 3 SD above the mean.

${ }^{4} 2$ outliers were replaced with values at 3 SD above the mean.

${ }^{5}$ Sum of $4 z$-scored items. 
Table 4

Inter-Correlations among Cellphone Use and Sleep Variables for Sample One $(N=273)$ and Sample Two $(N=152)$

\begin{tabular}{|c|c|c|c|c|c|c|c|c|c|c|c|c|c|}
\hline & 1. & 2. & 3. & 4. & 5. & 6. & 7. & 8. & 9. & 10. & 11. & 12. & 13. \\
\hline $\begin{array}{l}\text { 1. Estimated number of daily } \\
\text { texts }\end{array}$ & --- & $.24 * *$ & $.39 * * *$ & $.19 *$ & .14 & .06 & -.01 & .16 & .15 & .06 & .02 & .10 & .05 \\
\hline $\begin{array}{l}\text { 2. Estimated number of daily } \\
\text { cellphone call minutes }\end{array}$ & .08 & --- & $.30 * * *$ & .14 & -.02 & .03 & -.06 & .07 & .14 & .04 & .09 & -.08 & $-.24 * *$ \\
\hline $\begin{array}{l}\text { 3. Nighttime cellphone } \\
\text { notifications }\end{array}$ & $.20 * *$ & -.09 & --- & $.41 * * *$ & $.35^{* * *}$ & $.19^{*}$ & .13 & $.21^{*}$ & $.25^{* *}$ & $.19 *$ & .14 & $.21 * *$ & $.24 * *$ \\
\hline 4. Compulsive cellphone use & $.17^{* *}$ & -.01 & $.31 * * *$ & --- & $.34 * * *$ & $.51 * * *$ & 15 & $.17 *$ & .11 & .10 & $.36 * * *$ & $.18^{*}$ & $.31 * * *$ \\
\hline 5. Global sleep problems & -.03 & -.08 & $.22 * * *$ & $.18^{* *}$ & --- & $.44 * * *$ & $.55 * * *$ & $.68 * * *$ & $.43 * * *$ & $.54 * * *$ & $.57 * * *$ & $.55^{* * *}$ & $.62 * * *$ \\
\hline 6. Daytime sleepiness & .08 & -.09 & $.26 * * *$ & $.33 * * *$ & $.43^{* * *}$ & --- & $.31 * * *$ & $.25 * * *$ & .09 & .04 & $.50 * * *$ & $.17 *$ & $.44^{* * *}$ \\
\hline $\begin{array}{l}\text { 7. PSQI Subjective sleep } \\
\text { quality }\end{array}$ & -.02 & -.06 & .11 & .11 & $.71^{* * *}$ & $.29 * * *$ & --- & $.28 * * *$ & $.21^{*}$ & $.23 * *$ & $.26 * *$ & -.01 & $.36 * * *$ \\
\hline 8. $\quad$ PSQI Sleep latency & -.06 & -.08 & $.25 * * *$ & $.12 * 0$ & $.69 * * *$ & $.24 * * *$ & $.49 * * *$ & --- & .04 & $.29 * * *$ & $.31 * * *$ & $.31 * * *$ & $.24 * *$ \\
\hline 9. PSQI Sleep duration & .04 & -.02 & .09 & $13^{*}$ & $.56 * * *$ & $.20^{* *}$ & $.35^{* * *}$ & $.20^{* *}$ & --- & $.53^{* * *}$ & .02 & -.02 & .07 \\
\hline $\begin{array}{l}\text { 10. PSQI Habitual sleep } \\
\text { efficiency }\end{array}$ & -.05 & -.04 & .09 & .08 & $.58 * * *$ & .11 & $.30 * * *$ & $.23 * * *$ & $.50 * * *$ & --- & .14 & .05 & .05 \\
\hline 11. PSQI Sleep disturbances & $.21 * *$ & -.04 & $.33 * * *$ & $.18^{* *}$ & $.51^{* * *}$ & $.39 * * *$ & $.25 * * *$ & $.30 * * *$ & .10 & $.13^{*}$ & $\begin{array}{c}-- \\
\end{array}$ & $.26^{* *}$ & $.36 * * *$ \\
\hline $\begin{array}{l}\text { 12. PSQI Use of sleeping } \\
\text { medication }\end{array}$ & .01 & -.03 & .04 & .01 & $.59 * * *$ & $.14^{*}$ & $.30 * * *$ & $.29 * * *$ & .09 & $.13 *$ & $.27 * * *$ & --- & $.34^{* * *}$ \\
\hline 13. PSQI Daytime dysfunction & $-.16 *$ & -.08 & .04 & $.17^{* *}$ & $.53 * * *$ & $.51 * * *$ & $.32 * * *$ & $.20^{* *}$ & $.19 * *$ & $.13 *$ & $.24 * * *$ & $.19 * *$ & --- \\
\hline
\end{tabular}

Note. Sample One correlations are presented below the diagonal. Sample Two correlations are presented above the diagonal. 
${ }^{*} p<.05,{ }^{* *} p<.01,{ }^{* * *} p<.001$.

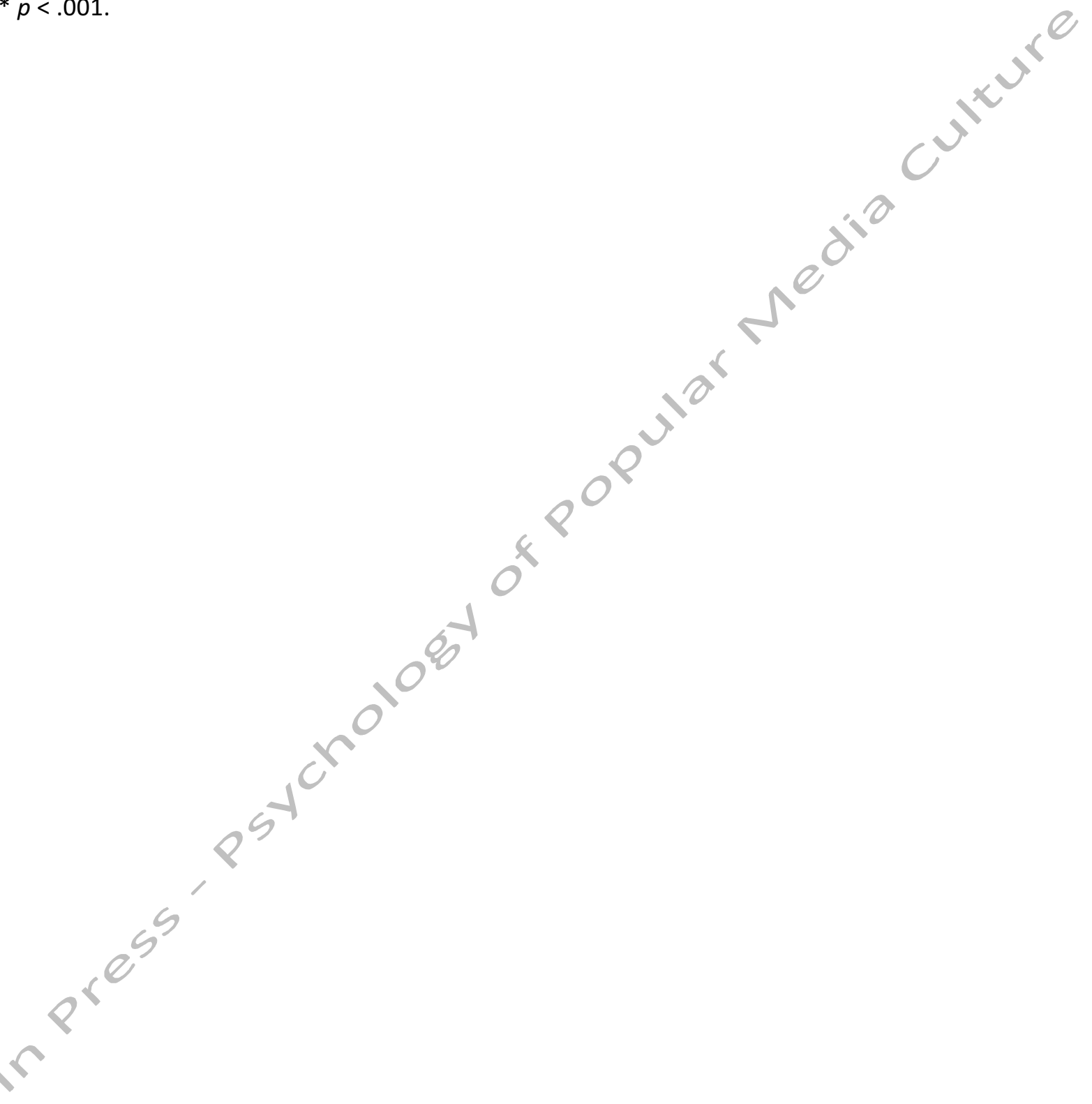


Table 5

Hierarchical Multiple Regression Analyses Predicting Global Sleep Problems

\begin{tabular}{|c|c|c|c|c|c|c|c|c|c|c|}
\hline \multirow[b]{2}{*}{ Predictors } & \multicolumn{5}{|c|}{ Sample One $(N=273)$} & \multicolumn{5}{|c|}{ Sample Two $(N=152)$} \\
\hline & $R^{2}$ & $\Delta R^{2}$ & $\beta$ & $t$ & $p$ & $R^{2}$ & $\Delta R^{2}$ & $\beta$ & $t$ & $p$ \\
\hline Block 1: & .00 & .00 & & & & .040 & $.04 *$ & & & \\
\hline Sex & & & -.02 & 0.39 & .696 & $e$ & & .20 & 2.54 & .012 \\
\hline Block 2: & .00 & .00 & & & $=$ & .08 & $.04 *$ & & & \\
\hline Sex & & & -.02 & 0.32 & .753 & & & .25 & 3.06 & .003 \\
\hline Estimated daily texts & & & -.03 & 0.41 & .685 & & & .20 & 2.47 & .015 \\
\hline Estimated daily call minutes & & & -.05 & 0.85 & .396 & & & -.11 & 1.27 & .205 \\
\hline Block 3: & .04 & $.04 * *$ & 8 & & & .21 & $.13 * * *$ & & & \\
\hline Sex & & & -.02 & 0.26 & .793 & & & .30 & 3.84 & .000 \\
\hline Estimated daily texts & & & -.07 & 1.10 & .277 & & & .07 & 0.87 & .384 \\
\hline Estimated daily call minutes & & o & -.03 & 0.56 & .578 & & & -.21 & 2.59 & .011 \\
\hline Nighttime cellphone notifications & & & .21 & 3.35 & .001 & & & .41 & 4.89 & .000 \\
\hline Block 4: & .06 & $.02 *$ & & & & .24 & $.03 *$ & & & \\
\hline Sex & 10 & & -.04 & 0.63 & .532 & & & .27 & 3.48 & .001 \\
\hline Estimated daily texts & 5 & & -.09 & 1.37 & .173 & & & .06 & 0.75 & .453 \\
\hline Estimated daily call minutes & & & -.03 & 0.56 & .575 & & & -.20 & 2.58 & .011 \\
\hline Nighttime cellphone notifications & & & .17 & 2.63 & .009 & & & .33 & 3.72 & .000 \\
\hline Compulsive cellphone use & & & .13 & 2.08 & .038 & & & .19 & 2.42 & .017 \\
\hline
\end{tabular}

${ }^{*} p<.05 .{ }^{* *} p<.01 .{ }^{* * *} p<.001$. 


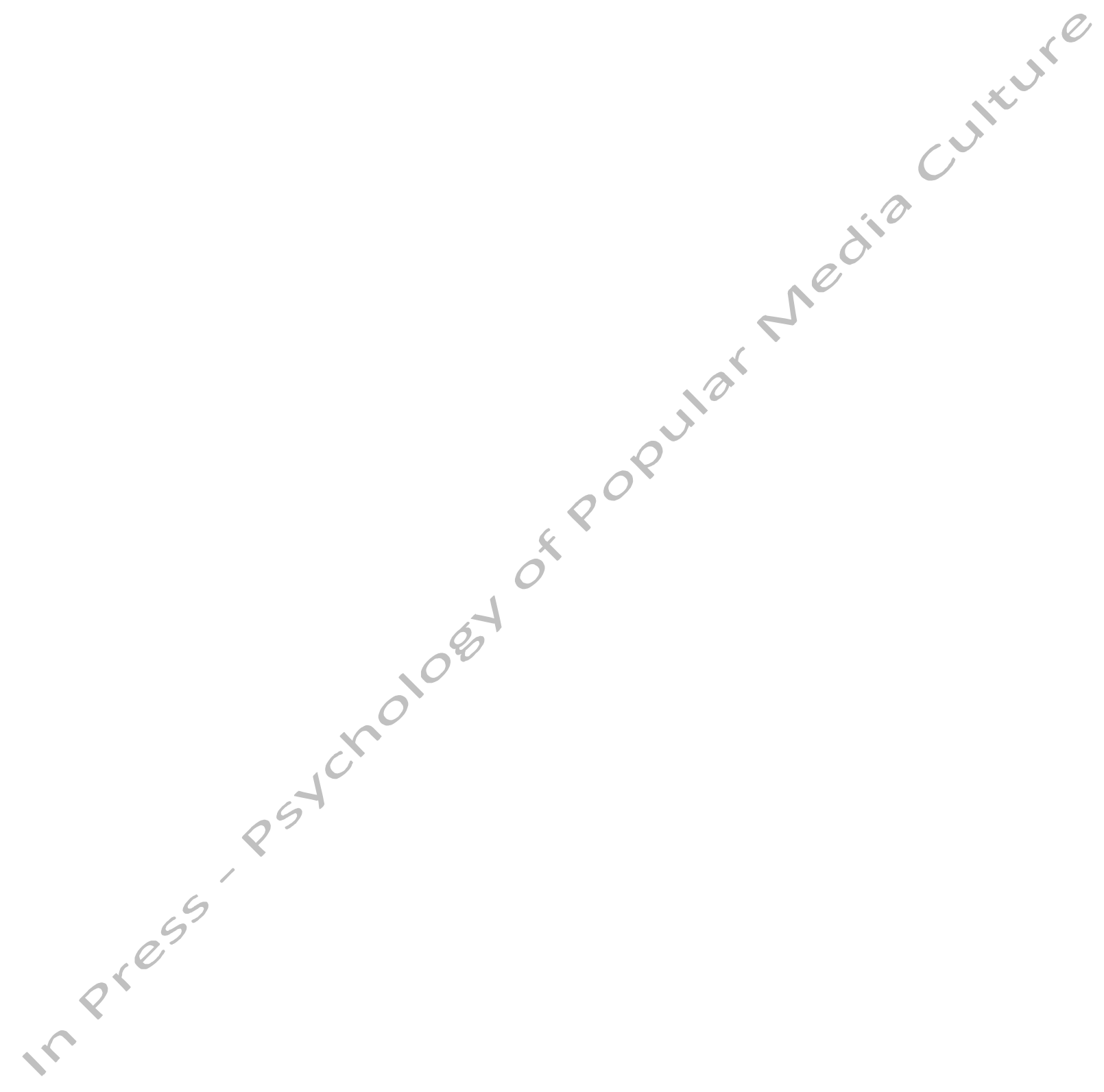


Table 6

Hierarchical Multiple Regression Analyses Predicting Daytime Sleepiness

\begin{tabular}{|c|c|c|c|c|c|c|c|c|c|c|}
\hline & \multicolumn{5}{|c|}{ Sample One $(N=273)$} & \multicolumn{5}{|c|}{ Sample Two $(N=152)$} \\
\hline Predictors & $R^{2}$ & $\Delta R^{2}$ & $\beta$ & $t$ & $p$ & $R^{2}$ & $\Delta R^{2}$ & $\beta$ & $t$ & $p$ \\
\hline Block 1: & .00 & .00 & & & & .010 & .01 & & & \\
\hline Sex & & & .00 & 0.07 & .946 & $e_{1}$ & & .08 & 0.96 & .337 \\
\hline Block 2: & .01 & .01 & & & C. & .01 & .01 & & & \\
\hline Sex & & & .02 & 0.35 & .723 & & & .09 & 1.04 & .302 \\
\hline Estimated daily texts & & & .09 & 1.50 & .135 & & & .08 & 0.90 & .368 \\
\hline Estimated daily call minutes & & & -.07 & 1,20 & 232 & & & .00 & 0.04 & .965 \\
\hline Block 3: & .05 & $.04 * *$ & 8 & & & .05 & $.03^{*}$ & & & \\
\hline Sex & & & .03 & 0.42 & .674 & & & .11 & 1.31 & .193 \\
\hline Estimated daily texts & & & .05 & 0.80 & .426 & & & .01 & 0.12 & 909 \\
\hline Estimated daily call minutes & & 8 & -.06 & 0.90 & .367 & & & -.05 & 0.54 & .591 \\
\hline Nighttime cellphone notifications & & & .21 & 3.43 & .001 & & & .21 & 2.25 & .026 \\
\hline Block 4: & .12 & $.07 * * *$ & & & & .26 & $.21 * * *$ & & & \\
\hline Sex & 10 & & -.02 & 0.34 & .733 & & & .03 & 0.45 & .654 \\
\hline Estimated daily texts & 8 & & .01 & 0.23 & .822 & & & -.02 & 0.22 & .823 \\
\hline Estimated daily call minutes & & & -.06 & 0.94 & .349 & & & -.04 & 0.48 & .634 \\
\hline Nighttime cellphone notifications & & & .13 & 2.12 & .035 & & & .00 & 0.01 & .989 \\
\hline Compulsive cellphone use & & & .28 & 4.40 & .000 & & & .51 & 6.39 & .000 \\
\hline
\end{tabular}

${ }^{*} p<.05 .{ }^{* *} p<.01 .{ }^{* * *} p<.001$. 


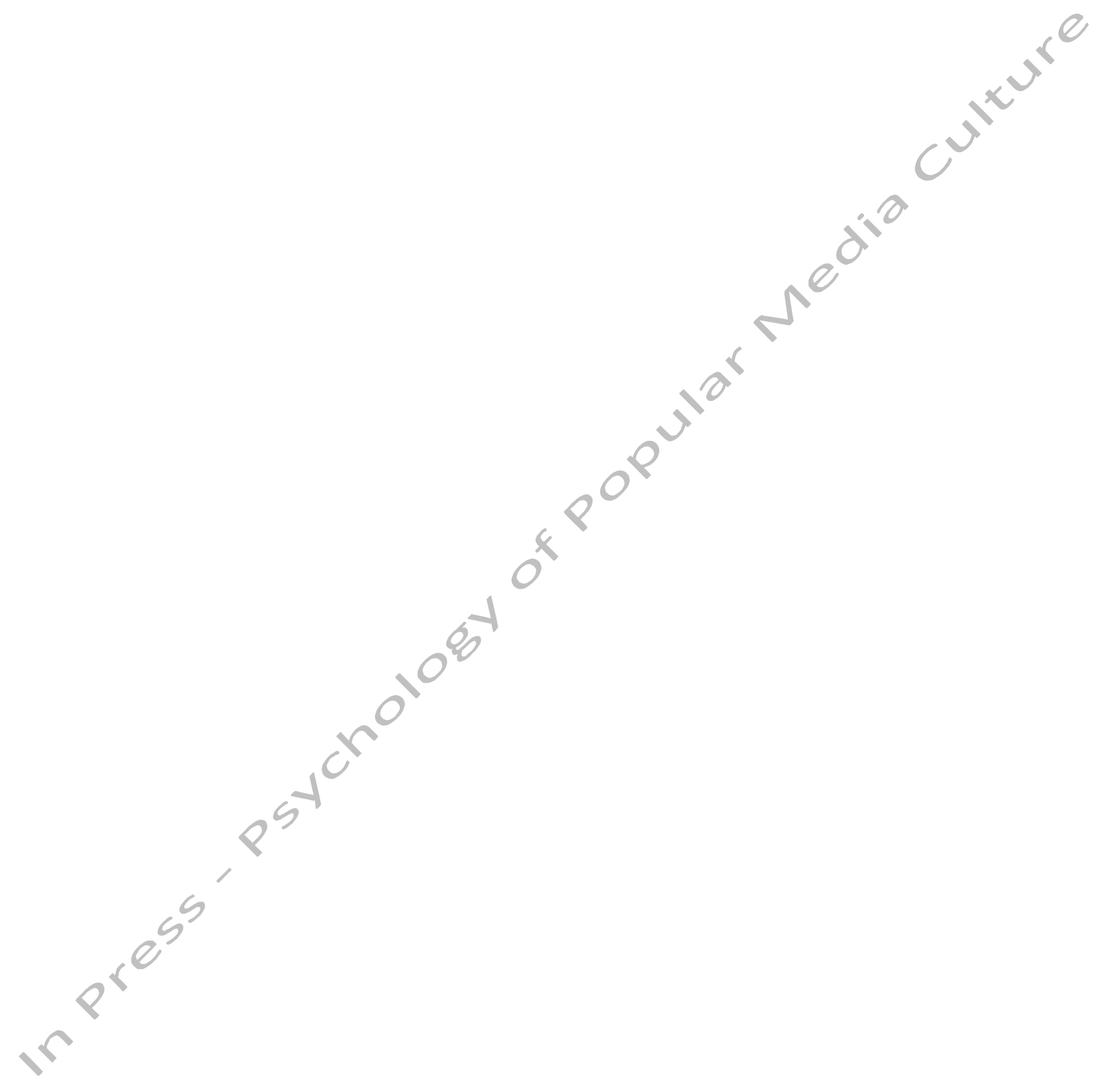

